\section{Influenza Vaccination Coverage among Health Professionals before and after the $A(H 1 N 1)$ Influenza Pandemic in France}

To the Editor-We read with interest the study by Guthmann et $\mathrm{al}^{1}$ on influenza vaccination coverage 1 year after the A(H1N1) influenza pandemic in France. The authors conducted a phone survey among a representative sample of households in mainland France. The sample included 198 healthcare workers (HCWs), and vaccination coverage in this group was $27.6 \%$. On the basis of the fact that a previous study performed with a similar methodology showed vaccination coverage of $33.9 \%$ among HCWs, the authors concluded that the controversies related to the pandemic vaccination campaign of 2009-2010 have not had a negative impact on subsequent seasonal influenza vaccination cover- age. ${ }^{2}$ Being occupational physicians in a university hospital, we did not have this feeling, and we therefore performed a short survey among various hospitals in France. We sent a questionnaire concerning influenza vaccination coverage of health professionals to 150 occupational physicians working in different hospitals in France. We received 30 answers, mostly from university hospitals, representing more than 150,000 health professionals (Table 1). Briefly, all hospitals but one reported a sharp decrease, ranging between $-21 \%$ and $-61 \%$, in vaccination coverage between the winter of 2008-2009, before the $\mathrm{A}(\mathrm{H} 1 \mathrm{N1})$ pandemic, and the winter of 2010-2011, after the A(H1N1) pandemic. The mean decrease in vaccination coverage was $42 \%$ and was highly significant $(P<.001)$.

Since the answers were provided by occupational health physicians who recorded only the vaccinations performed in the occupational health departments, coverage might be un-

TABLE 1. Vaccination Coverage of Healthcare Workers in France before and after the A(H1N1) Pandemic

\begin{tabular}{|c|c|c|c|c|}
\hline \multirow[b]{2}{*}{ Hospital } & \multirow[b]{2}{*}{ No. of workers } & \multicolumn{2}{|c|}{$\begin{array}{c}\text { Vaccination } \\
\text { coverage, no. (\%) }\end{array}$} & \multirow[b]{2}{*}{ Difference, $\%$} \\
\hline & & $2008-2009$ & $2010-2011$ & \\
\hline General Hospital, Alençon & 669 & $44(7)$ & $31(5)$ & -30 \\
\hline General Hospital, Deauville & 632 & $155(25)$ & $79(13)$ & -49 \\
\hline General Hospital, Digne & 1,200 & $117(10)$ & $97(8)$ & -17 \\
\hline General Hospital, Haguenau & 1,900 & $446(23)$ & $250(13)$ & -44 \\
\hline General Hospital, Jean-Verdier & 1,515 & $750(50)$ & $407(27)$ & -46 \\
\hline General Hospital, Le Havre & 4,500 & $1,013(23)$ & $499(11)$ & -51 \\
\hline General Hospital, Loire & 1,770 & $557(31)$ & $285(16)$ & -49 \\
\hline General Hospital, Mont de Marsan & 3,200 & $500(16)$ & $250(8)$ & -50 \\
\hline General Hospital, Pau & 1,200 & $175(15)$ & $69(6)$ & -61 \\
\hline General Hospital, Vendée & 4,200 & $800(19)$ & $493(12)$ & -38 \\
\hline Public Maternity Hospital, Nancy & 1,100 & $304(28)$ & $190(17)$ & -38 \\
\hline Red Cross Hospital, Rouen & 157 & $54(34)$ & $32(20)$ & -41 \\
\hline University Hospital, Besancon & 6,327 & $446(7)$ & $613(10)$ & 37 \\
\hline University Hospital, Bordeaux & 14,000 & $3,022(22)$ & $1,868(13)$ & -38 \\
\hline University Hospital, Brest & 7,820 & $2,026(26)$ & $792(10)$ & -61 \\
\hline University Hospital, Caen & 6,800 & $2,300(34)$ & $1,300(19)$ & -43 \\
\hline University Hospital, Créteil & 2,300 & $915(40)$ & $593(26)$ & -35 \\
\hline University Hospital, Lille & 13,194 & $2,900(22)$ & $1,658(13)$ & -43 \\
\hline University Hospital, Limoges & 7,200 & $1,656(23)$ & $612(9)$ & -63 \\
\hline University Hospital, Lyon & 4,550 & $729(16)$ & $505(11)$ & -31 \\
\hline University Hospital, Lyon & 2,312 & $578(25)$ & $472(20)$ & -18 \\
\hline University Hospital, Lyon & 5,200 & $850(16)$ & $460(9)$ & -46 \\
\hline University Hospital, Lyon & 6,000 & $1,241(21)$ & $722(12)$ & -42 \\
\hline University Hospital, Marseille & 16,000 & $2,375(15)$ & $1,700(11)$ & -28 \\
\hline University Hospital, Nancy & 9,000 & $1,454(16)$ & $715(8)$ & -51 \\
\hline University Hospital, Nantes & 12,000 & $1,434(12)$ & $1041(9)$ & -27 \\
\hline University Hospital, Paris & 2,700 & $473(18)$ & $374(14)$ & -21 \\
\hline University Hospital, Paris & 4,062 & $771(19)$ & $354(9)$ & -54 \\
\hline University Hospital, Rennes & 7,800 & $1,675(21)$ & $834(11)$ & -50 \\
\hline University Hospital, Rouen & 9,500 & $1,032(11)$ & $692(7)$ & -33 \\
\hline Total & 158,808 & $30,792(19)$ & $17,987(11)$ & -42 \\
\hline
\end{tabular}


derestimated if some workers received influenza vaccine outside the hospital. Nevertheless, such underestimation would be of the same order of magnitude in 2008 and 2010; therefore, it probably would not affect the trend.

Thus, we can conclude that there has been a decrease in influenza vaccination coverage among health professionals in France, which probably reflects the real impact of the controversies related to pandemic vaccination campaign among HCWs in France.

In 2009, the government of France, which has a population of around 63.5 million, brought in 94 million doses of $\mathrm{A}(\mathrm{H} 1 \mathrm{~N} 1)$ pandemic vaccines. At the time, there had been ongoing public controversy about the safety of new pandemic vaccines and the rationale for mass vaccination of the whole population. ${ }^{3}$ In a cross-sectional online survey performed among 2,253 representative French adults, Schwarzinger et $\mathrm{al}^{4}$ have shown that alarming public health messages aimed at increasing the perception of risk severity had been counteracted by daily personal experience, which did not confirm the threat, while vaccine safety was a major issue. Furthermore, although French general practitioners had positive attitudes toward $\mathrm{A}(\mathrm{H} 1 \mathrm{~N} 1)$ influenza pandemic vaccination, they had not been allowed to participate in the pandemic vaccination campaign for logistical reasons.

This dissonance has been responsible for the fact that pandemic vaccine uptake rates have remained low in both hospitals and mass vaccination centers in France. It has been demonstrated that greater knowledge and positive attitudes toward influenza and vaccination have a significant positive association with vaccination coverage among nurses and have an even more positive effect on physicians. ${ }^{5}$ We think that all the controversies that surrounded the $A(H 1 N 1)$ influenza pandemic vaccination campaign in France have had a marked effect on the attitudes of HCWs toward seasonal influenza vaccine, which explains the dramatic decrease in coverage of French HCWs against seasonal influenza.

\section{ACKNOWLEDGMENTS}

We thank all the occupational physicians who answered the questionnaire.

Potential conflicts of interest. All authors report no conflicts of interest relevant to this article. All authors submitted the ICMJE Form for Disclosure of Potential Conflicts of Interest, and the conflicts that the editors consider relevant to this article are disclosed here.

\section{Jean-François Gehanno, $\mathrm{MD}, \mathrm{PhD} ;^{1}$ Laetitia Rollin, $\mathrm{MD}^{1}$}

Affiliations: 1. Institute of Occupational Health, Rouen University Hospital and University of Rouen, France.

Address correspondence to J.-F. Gehanno, $\mathrm{MD}, \mathrm{PhD}$, Department of Occupational Medicine, Rouen University Hospital, 1 rue de Germont, 76000 Rouen, France (Jean-Francois.gehanno@chu-rouen.fr). Infect Control Hosp Epidemiol 2012;33(7):757-758

(C) 2012 by The Society for Healthcare Epidemiology of America. All rights reserved. 0899-823X/2012/3307-0017\$15.00. DOI: $10.1086 / 666338$

\section{REFERENCES}

1. Guthmann JP, Fonteneau L, Bonmarin I, Lévy-Bruhl D. Influenza vaccination coverage one year after the $A(\mathrm{H} 1 \mathrm{~N} 1)$ influenza pandemic, France, 2010-2011. Vaccine 2012;30:995-997.

2. Vaux S, Van Cauteren D, Guthmann JP, et al. Influenza vaccination coverage against seasonal and pandemic influenza and their determinants in France: a cross-sectional survey. BMCPublic Health 2011;11:30.

3. Schwarzinger $M$, Verger $P$, Guerville $M A$, et al. Positive attitudes of French general practitioners towards $\mathrm{A} / \mathrm{H} 1 \mathrm{~N} 1$ influenzapandemic vaccination: a missed opportunity to increase vaccination uptakes in the general public? Vaccine 2010;28:2743-2748.

4. Schwarzinger M, Flicoteaux R, Cortarenoda S, Obadia Y, Moatti JP. Low acceptability of $\mathrm{A} / \mathrm{H} 1 \mathrm{~N} 1$ pandemic vaccination in French adult population: did public health policy fuel public dissonance? PLoS One 2010;5:e10199.

5. Zhang J, While AE, Norman IJ. Knowledge and attitudes regarding influenza vaccination among nurses: a research review. Vaccine 2010;28:7207-7214.

\section{Neurosurgical Case Investigation of Postflood Pseudomeningitis due to Mold}

To the Editor-Limited data are available for postflood pseudomeningitis cases. We report a case investigation of postoperative pseudomeningitis due to mold in a neurosurgical patient. From October 14 to November 24, 2011, Thammasat University Hospital (TUH) was closed due to excessive floods in the Pratumthani province of central Thailand. Before TUH reopened, a through environmental cleaning was performed, and hospital preparedness plans included compliance with a postflood checklist from the Centers for Disease Control and Prevention. ${ }^{1}$ Air sampling, using Microbiological Air Sampler NT 100 (Merck), was performed to assess fungal bioburden in operating rooms (ORs); samples were inoculated onto sterile blood and Sabouraud agars at each environmental test site, with the standard reference of less than $500 \mathrm{CFU} / \mathrm{m}^{3}$ total fungal bioburden as the upper limit of normal. ${ }^{2}$ Five of $20(25 \%)$ ORs met the criteria to reopen. On November 25 , 2011 , select units of the hospital reopened, including medicine, surgery, 1 intensive care unit, and the 5 ORs that met the criteria to reopen.

On March 10, 2012, 3 months after TUH reopened, the Infectious Diseases Division was notified about a neurosurgical patient with persistent postoperative fevers. The case was a 45-year-old man with no underlying medical conditions who underwent emergency evacuation of an epidural hematoma after a vehicular accident. The emergent case was performed in an OR that was not yet reopened for routine procedures. On postoperative-day 4 , the patient had sustained fever, and the initial workup revealed a right lower lobe infiltrate, sputum Gram's stain with gram-negative coccobac- 